\title{
BMJ Open Treatment of faecal incontinence using allogeneic-adipose-derived mesenchymal stem cells: a study protocol for a pilot randomised controlled trial
}

\author{
Eun Jung Park, ${ }^{1}$ Jeonghyun Kang, ${ }^{1}$ Seung Hyuk Baik ${ }^{2}$
}

To cite: Park EJ, Kang J, Baik SH. Treatment of faecal incontinence using allogeneic-adipose-derived mesenchymal stem cells: a study protocol for a pilot randomised controlled trial. BMJ Open 2016;6:e010450. doi:10.1136/bmjopen-2015010450

- Prepublication history for this paper is available online. To view these files please visit the journal online (http://dx.doi.org/10.1136/ bmjopen-2015-010450)

Received 4 November 2015 Revised 7 January 2016 Accepted 21 January 2016

CrossMark

\begin{abstract}
${ }^{1}$ Division of Colon and Rectal Surgery, Department of Surgery, Gangnam Severance Hospital, Yonsei University College of Medicine, Seoul, Republic of Korea

2Department of Surgery, Gangnam Severance Hospital, Yonsei University College of Medicine, Seoul, Republic of Korea
\end{abstract}

\section{Correspondence to}

Professor Seung Hyuk Baik; whitenoja@yuhs.ac

\begin{abstract}
Introduction: Faecal incontinence is a distressing condition with recurrent uncontrolled passage of faecal material. Although faecal incontinence may cause psychological depression and social isolation, previous treatments have been limited. Recently, regenerative treatment has been developed using mesenchymal stem cells. Especially, there are possibilities that adipose-tissue-derived stem cells can be effective to treat a degenerated anal sphincter that is causing faecal incontinence. Therefore, this study aimed to investigate the safety and efficacy of using allogeneic-adipose-derived mesenchymal stem cells in the treatment of the anal sphincter of patients with faecal incontinence.
\end{abstract}

Methods and analysis: This study is a randomised, prospective, dose escalation, placebo-controlled, single-blinded, single-centre trial with two parallel groups. The safety test is performed by an injection of allogeneic-adipose-derived mesenchymal stem cells (ALLO-ASCs) into the anal sphincter with dose escalation $\left(3 \times 10^{7}, 6 \times 10^{7}\right.$ and $9 \times 10^{7}$ cells, sequentially). After confirming the safety of the stem cells, an efficacy test is performed by this dose in the experimental group. The experimental group will receive ALLO-ASCs mixed with fibrin glue into the anal sphincter, and the placebo group will receive $0.9 \%$ normal saline injection mixed with fibrin glue. The primary end point is to assess the safety of ALLO-ASCs after the injection into the anal sphincter, and the secondary end point is to compare the efficacy of ALLO-ASC injection with fibrin glue in patients with faecal incontinence.

Ethics and dissemination: The study protocol was approved by the Ministry of Food and Drug Safety and the Ministry of Health \& Welfare, in the Republic of Korea. The informed consent form was approved by the institutional review board of Gangnam Severance Hospital (IRB approval number 3-2014-0271). Dissemination of the results will be presented at a conference and in peer-reviewed publications.

Trial registration number: NCT02384499; Preresults.

\section{Strengths and limitations of this study}

- This study is the first randomised clinical trial for the treatment of faecal incontinence using allogeneic-adipose-derived mesenchymal stem cells (ALLO-ASCS), as a phase I study.

- The results of this study are expected to determine a safe dose of ALLO-ASCs injection into the anal sphincter by dose-escalation.

- The clinical outcomes and efficacy after ALLO-ASC injection are evaluated objectively by Wexner score, anorectal manometry and endorectal ultrasound.

- This trial can suggest the possibility of a new treatment for faecal incontinence.

- The sample size of this study has a limitation regarding power of observation, because this study is a pilot randomised controlled trial.

\section{INTRODUCTION}

Faecal incontinence is a distressing condition with recurrent uncontrolled passage of faecal material. It is defined as an unintentional loss of stool or flatus for at least 1 month, associated with faecal impaction, diarrhoea or non-structural anal sphincter dysfunction in a patient with more than 4 years of developmental age. ${ }^{1}{ }^{2}$ Although it is a benign non-functional symptom, patients may have psychological depression as well as be confined to limited social activities. The prevalence of faecal incontinence is estimated to be about $1.5 \%$ in the overall population and $18 \%$ in people more than 65 years old. ${ }^{3}$ Although it tends to be underestimated because of concealment and embarrassment, faecal incontinence is the second most common cause of institutionalisation with increasing rates in the elderly. ${ }^{4}$

There are multifactorial causes of faecal incontinence related to anatomical or 
neurological insufficiency of the anal sphincter. Treatment of faecal incontinence has been performed by conservative or surgical treatments. Medical therapies using bulking or constipating agents as well as biofeedback have been used for mild symptoms of faecal incontinence. ${ }^{5}{ }^{6}$ Sacral nerve stimulation was developed to enforce neuromodulation of the anal sphincter using implantable devices. ${ }^{7}$ In those with sphincter injuries and severe symptoms, surgical treatment such as sphincteroplasty, muscle transposition, artificial bowel sphincteroplasty and faecal diversions, have so far been performed. However, because these treatments are still controversial in effectiveness, regenerative treatment of the anal sphincter has been developed using mesenchymal stem cells. Since mesenchymal stem cells have pluripotent abilities to differentiate into osteocytes, myocytes, chondrocytes and adipocytes, they are regarded to have benefits to improve muscle contractile function by tissue regeneration. ${ }^{8}$

There have been several efforts to treat faecal incontinence by using mesenchymal stem cells. ${ }^{8-12}$ Frudinger et al used an autologous muscle-derived cell injection to treat anal incontinence that had developed from obstetric trauma. According to their report, 10 women suffering from anal incontinence showed safety and improved symptoms after an injection of autologous myoblast. ${ }^{9}$ In the 5-year follow-up, there was improvement of anal incontinence as well as quality of life. ${ }^{11}$

Recently, human adipose-tissue-derived mesenchymal stem cells (ASCs) have been used for treatment of perianal fistulas, including Crohn's disease. ${ }^{12}{ }^{13}$ In phase II clinical trials of Crohn's fistulas, autologous ASCs demonstrated favourable therapeutic outcomes. ${ }^{13}$ Moreover, adipose-tissue has the benefit of obtaining higher rates of mesenchymal stem cells and is more available than other bodies. Since ASCs have the abilities of both suppression of the inflammatory response and differentiation, it has potential benefits to repair damaged tissues. ${ }^{14}$ In these aspects of stem cell regeneration, we can hypothesise that ASCs can be used to treat a degenerated anal sphincter that is causing faecal incontinence. Therefore, this study aimed to investigate the safety and efficacy of allogeneic-adipose-derived mesenchymal stem cell (ALLO-ASC) injection into the anal sphincter in patients with faecal incontinence as a phase I clinical trial.

\section{METHODS AND ANALYSIS \\ Study design}

This study is a prospective, randomised, dose escalation, placebo-controlled, single-blinded, single-centre, phase I clinical trial with two parallel groups. It is being conducted in Gangnam Severance Hospital, Yonsei University College of Medicine in Seoul, Korea. This trial is registered with ClinicalTrial.gov (NCT02384499). The total study period is 2 years, from December 2014 to November 2016.
The study is composed of a safety test and an efficacy test. The safety test is carried out by dose escalation of ALLO-ASC. ALLO-ASCs are injected into the anal sphincter, using three different amounts. The patients in group 1 will receive $3 \times 10^{7}$ cells, with $6 \times 10^{7}$ cells for group 2 and $9 \times 10^{7}$ cells for group 3 , sequentially. After completing the safety test, a safe dose with the most effective clinical outcomes will be determined by assessing the changes of the Wexner score, the pressure of the anal sphincter and the score of patients' satisfaction. After analysing the average values of these parameters in each group, the dose that has the highest change with statistical significance will be determined for the efficacy test.

The efficacy test is performed by comparing the experimental group and the placebo group. The six patients in the experimental group will receive ALLO-ASC injection mixed with fibrin glue (Greenplast, Seoul, Korea) into the anal sphincter, while the six patients in the placebo group will receive $0.9 \%$ normal saline injection mixed with fibrin glue. The detailed trial flow is described in figure 1.

\section{Study population}

Inclusion criteria

- Participants at least 19 years old

- Patient received previous treatments for faecal incontinence, such as medical therapy, biofeedback or sacral nerve stimulation of more than 2 months, with a Wexner score $\geq 8$

- Transanal ultrasonography: presents a continuous pattern of the anal sphincter

- Anal manometry: decreased anal pressures are less than normal level

- Patients are negative for urine $\beta$-human chorionic gonadotropin in the screening test

- An informed consent form has been signed by the patient

\section{Exclusion criteria}

- Participation in another clinical trial within the past 30 days

- History of anorectal surgery within the previous 6 months

- History of malignant tumour surgery within the previous 5 years

- Patients requiring anorectal surgical treatments

- History of artificial sphincter surgery

- History of vaginal delivery within the past 6 months

- Medical history of variant Creutzfeld-Jakobs disease or related diseases

- Allergy to bovine-derived materials, fibrin glue or anaesthetics

- Autoimmune disease

- Active tuberculosis

- Pregnancy or breastfeeding women

- Unwillingness to use contraceptive methods

- Patients with inflammatory bowel disease 


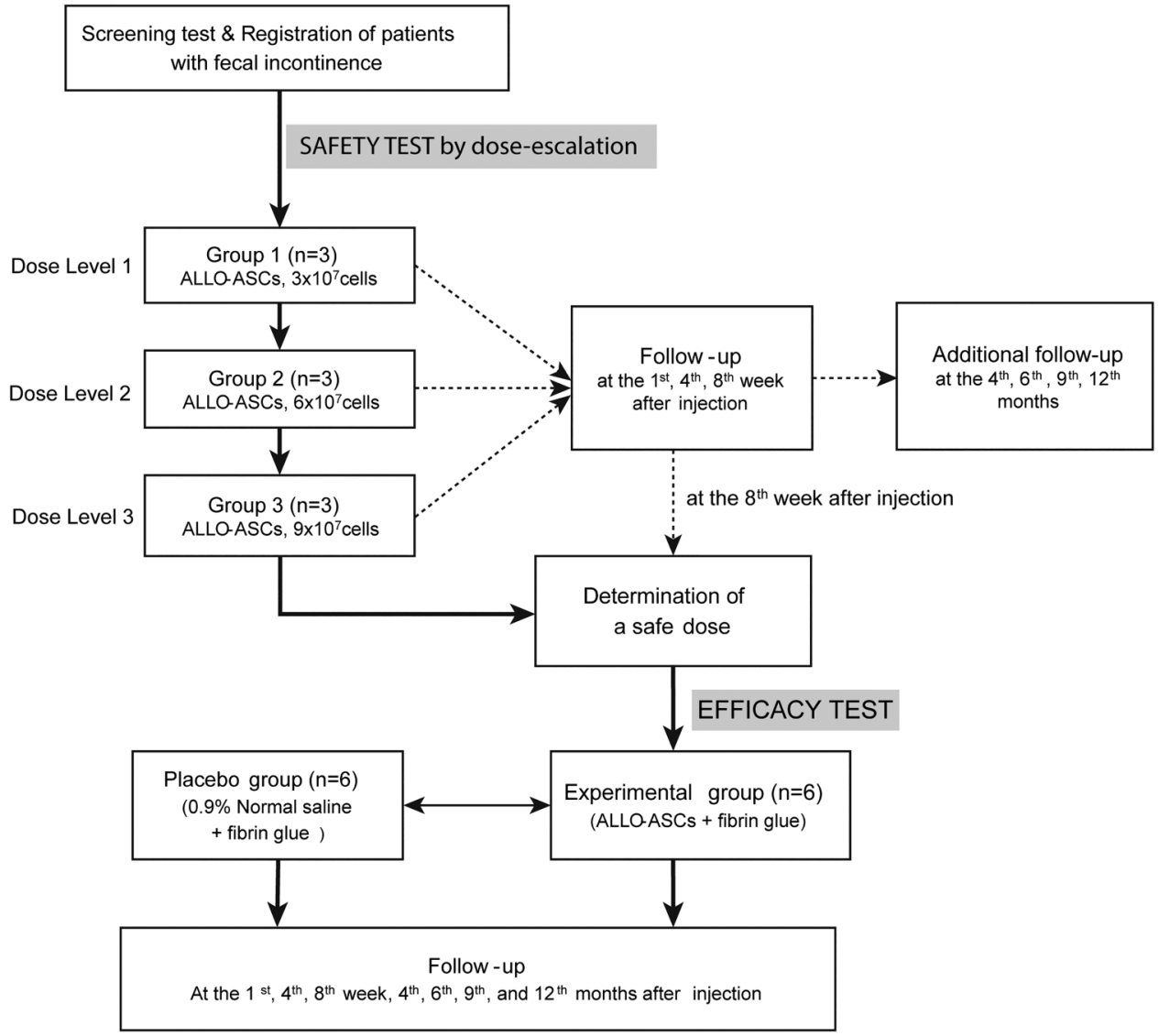

Figure 1 Trial schema.

- Alcohol or drug abusers

- Use of cytotoxic agents within the past 30 days

- Patients who have severe constipation $(<2$ times/ week), anal fistula, rectal prolapse, spinal cord injury, multiple sclerosis and Parkinson's disease

- Patients with haematological diseases, immunodeficiency, fever, acute disease or severe chronic disease

Owing to this study aims to investigate the regenerative effects of ALLO-ASCs on the anal sphincter, we exclude patients who have had previous anal sphincter injuries or who had undergone anal surgeries that involved the anal sphincter, before this trial. Patients who need to treat a perianal disease or who have a comorbid disease, which can be confounding factors, have also been excluded. In addition, patients with a history of malignant tumour, inflammatory bowel disease or pregnancy, are excluded.

\section{Screening and implementation}

Before enrolment, the investigator assesses the eligibility of potential participants according to the inclusion and exclusion criteria. After getting informed consent, the screening tests are performed in an outpatient clinic. The detailed screening items to assess in the participants are described below.

Screening items assessed by an investigator:

1. Patient characteristics

- Medical and concomitant drug histories
- Physical examination and vital signs

- Blood samplings for serological test, such as complete blood count, biochemical test, $\mathrm{ABO}$ typing, HBV surface antigen, hepatitis $\mathrm{C}$ virus, HIV and Venereal Disease Research Laboratory

- Urinalysis including urine $\beta$-hCG

- Digital rectal examination

2. Objective outcome measures

- Wexner score

- Anorectal manometry

- Endorectal ultrasound

ALLO-ASC injection into the anal sphincter should be performed within 1 month from the screening test. On the day of surgical intervention, the investigator again confirms the eligibility of participants. Then, the participants will have a serological test, urinalysis, immunological test $(\mathrm{CD} 4 / \mathrm{CD} 8)$, digital rectal examination and Wexner score (table 1), before the ALLO-ASC injection. All detailed procedures are described in table 2.

\section{Sample size and randomisation}

Since this trial is a phase I pilot study, each group is composed of three patients, to examine the safety of the ALLO-ASC injection according to dose escalation. The sample size of the safety test was based on the traditional $3+3$ dose escalation design. ${ }^{15}$ In the efficacy test, sample size calculation was based on the assumption that the standard variation of the Wexner score between the 
Table 1 Wexner score (Cleveland Clinic Continence Scoring System)

\begin{tabular}{lllllll}
\hline Items & Pattern of incontinence & Never & Rarely & Sometimes & Usually & Always \\
\hline 1 & Solid & 0 & 1 & 2 & 3 & 4 \\
2 & Liquid & 0 & 1 & 2 & 3 & 3 \\
3 & Gas & 0 & 1 & 2 & 3 & 4 \\
4 & Wears pad & 0 & 1 & 2 & 3 & 4 \\
5 & Lifestyle alteration & 0 & 1 & 2 & 3 \\
\hline
\end{tabular}

Never (0); Rarely ( $<1 /$ month); Sometimes ( $<1 /$ week, $\geq 1 /$ month); Usually ( $<1 /$ day, $\geq 1 /$ week); Always ( $\geq 1 /$ day); 0 , perfect approximately 20 , complete incontinence.

experimental and the control group was 8 . Then the sample size was determined by $\alpha$ value of $0.05, \beta$ value of 0.2 , and a statistical power of 0.8 with 2-sided $p$ values using the PASS 14 software (NCSS LLC, Kaysville, Utah, USA). Therefore, there are totally 12 patients, and each group has 6 patients chosen by randomisation. Randomisation is preceded by the SAS V.9.1 (SAS Inc, Cary, North Carolina, USA) to generate random numbers. After registration, an investigator randomises and assigns the participants to an experimental or a placebo group by a single-blinded design.

\section{Statistical analysis}

All patients who enrol in this trial are treated with an intention-to-treat analysis. Per-protocol analysis is used to evaluate the efficacy of included patients who received ALLO-ASC injections and completed visiting schedules. The different results between the screening and follow-up period during the safety test are analysed by the student t test, $\chi^{2}$ test or Fisher's exact test. The differences of the Wexner score, anorectal manometry, endorectal ultrasound, patient satisfaction survey (table 3) and faecal incontinence quality of life instrument (FIQL), ${ }^{16}$

Table 2 Schedule of enrolment, intervention and assessment

\begin{tabular}{|c|c|c|c|c|c|c|c|c|c|c|}
\hline \multirow{3}{*}{$\begin{array}{l}\text { Process } \\
\text { Timepoint }\end{array}$} & \multicolumn{10}{|l|}{ Study period } \\
\hline & \multirow{2}{*}{$\begin{array}{l}\text { Screening and Enrolment } \\
-30 \text { days }\end{array}$} & \multirow{2}{*}{$\begin{array}{l}\text { Allocation } \\
0\end{array}$} & \multicolumn{4}{|c|}{$\begin{array}{l}\text { Postallocation } \\
\text { period (weeks) }\end{array}$} & \multicolumn{4}{|c|}{$\begin{array}{l}\text { Follow-up period } \\
\text { (months) }\end{array}$} \\
\hline & & & $\mathbf{3 h}$ & 1 & 4 & 8 & 4 & 6 & 9 & 12 \\
\hline \multicolumn{11}{|l|}{ Enrolment and screening } \\
\hline Eligibility screening & $\mathrm{X}$ & $\mathrm{X}$ & & & & & & & & \\
\hline Informed consent & $x$ & & & & & & & & & \\
\hline Medical or drug history & $\mathrm{X}$ & & & & & & & & & \\
\hline Physical examination/vital signs & $x$ & $\mathrm{X}$ & & $\mathrm{X}$ & $\mathrm{X}$ & $X$ & $x$ & $\mathrm{X}$ & $x$ & $x$ \\
\hline Urine $\beta-\mathrm{hCG}^{*}$ & $x$ & & & & & $x$ & & & & $x$ \\
\hline Serological and biochemical tests & $x$ & $\mathrm{X}$ & & & & $\mathrm{X}$ & & $\mathrm{X}$ & & $x$ \\
\hline Urinalysis & $x$ & $\mathrm{X}$ & & & & $\mathrm{X}$ & & $\mathrm{x}$ & & $x$ \\
\hline $\mathrm{ABO} \mathrm{Rh}$ & $\mathrm{X}$ & & & & & & & & & \\
\hline HBsAg & $\mathrm{X}$ & & & & & & & & & \\
\hline HCV \& HIV & $x$ & & & & & & & & & \\
\hline VDRL & $x$ & & & & & & & & & \\
\hline Digital rectal examination & $x$ & $x$ & $\mathrm{X}$ & $x$ & $\mathrm{X}$ & $\mathrm{X}$ & $x$ & $\mathrm{X}$ & $x$ & $x$ \\
\hline \multicolumn{11}{|l|}{ Intervention } \\
\hline ALLO-ASC injection & & $\mathrm{X}$ & & & & & & & & \\
\hline \multicolumn{11}{|l|}{ Assessment } \\
\hline Local tolerability & & & $\mathrm{X}$ & $\mathrm{X}$ & $X$ & $x$ & $x$ & $x$ & $x$ & $\mathrm{X}$ \\
\hline Immunological test (CD4/CD8) & & $X$ & & $X$ & $\mathrm{X}$ & & & & & \\
\hline Wexner score & $\mathrm{X}$ & $X$ & & $\mathrm{X}$ & $X$ & $\mathrm{X}$ & $\mathrm{X}$ & $\mathrm{X}$ & $\mathrm{X}$ & $\mathrm{X}$ \\
\hline Anorectal manometry & $x$ & & & & $\mathrm{X}$ & $x$ & $x$ & $x$ & $x$ & $x$ \\
\hline Endorectal ultrasonography & $x$ & & & & $\mathrm{X}$ & & & & & $x$ \\
\hline Patient satisfaction survey & & & & & $\mathrm{X}$ & $x$ & $x$ & $x$ & $x$ & $x$ \\
\hline FIQL & & & & $\mathrm{X}$ & $\mathrm{X}$ & $\mathrm{X}$ & $\mathrm{X}$ & $x$ & $\mathrm{X}$ & $\mathrm{X}$ \\
\hline Stool diary & & $\mathrm{X}$ & $\mathrm{X}$ & $x$ & $X$ & $x$ & $x$ & $x$ & $x$ & $x$ \\
\hline Adverse events & & & $x$ & $x$ & $x$ & $x$ & $x$ & $x$ & $x$ & $x$ \\
\hline Concomitant medications & $x$ & $x$ & & $x$ & $x$ & $x$ & $x$ & $x$ & $x$ & $x$ \\
\hline
\end{tabular}

${ }^{*}$ Performed in fertile women.

†In the dose-escalation test, ALLO-ASCs are injected. In the efficacy test, a mixed solution of ALLO-ASCs with fibrin glue is injected in the experimental group.

ALLO-ASC, allogeneic-adipose-derived mesenchymal stem cells; $\beta$-hCG, $\beta$-human chorionic gonadotropin; HBsAg, HBV surface antigen; HCV, hepatitis C virus; FIQL, Faecal Incontinence Quality of Life Instrument; VDRL, Venereal Disease Research Laboratory. 
between the experimental and placebo groups, are analysed by the $t$ test or Wilcoxon rank sum test. All statistical analyses are performed using the SPSS V.20.0 (SPSS Inc, IBM Corp, Chicago, Illinois, USA) and SAS V.9.1 (SAS Inc, Cary, North Carolina, USA). p Value less than 0.05 is considered statistically significant.

\section{The characteristics of ALLO-ASCs}

This study uses ALLO-ASCs, which are manufactured at Anterogen Co, Ltd, and approved for clinical studies by the Korean Food and Drug Administration (Approval number: Clinical-839). The phenotypes of ALLO-ASCs are characterised by positivity for CD73, CD90 and CD 105, and negativity for CD34, CD45, CD14, CD11b, CD79 $\alpha$, CD19 and HLA-DR. According to the position statement of the International Federation for Adipose Therapeutics and Science (IFATS), and the International Society for Cellular Therapy (ISCT), ALLO-ASCs are plastic adherent fibroblast-like cells that can be differentiated into adipocyte, chondrocyte and osteocyte. In the immunophenotype, stromal-associated markers such as CD73 and CD90 are expressed. However, the hematopoietic-associated markers such as CD34 and CD45 are not expressed in ALLO-ASCs.

\section{Preparation of ALLO-ASCs}

After receiving informed consent, human subcutaneous fat tissues are harvested from the healthy adult donor. ALLO-ASCs are isolated from the lipo-aspirates of fat tissues. In this study, the ALLO-ASCs made from the same individual donors were used to maintain the consistency of the stem cells. According to the 'Guidelines on the Requirements for Quality Dossier of Biological Products in Clinical Trials' of the Korean Ministry of Food and Drug Safety (MFDS), donor suitability is assessed.

The fat tissues, which were obtained from lipo-aspirates, were washed with phosphate-buffered saline (PBS) and digested in an equal volume of $0.025 \%$ collagenase type I (Invitrogen, Gaithersburg, Maryland, USA) and PBS containing 1\% bovine serum albumin. We cultured the isolated stromal vascular fraction in Dulbecco's modified Eagle's Medium (DMEM), which is supplemented with $10 \%$ fetal bovine serum (FBS) and $1 \mathrm{ng} / \mathrm{mL}$ human basic-fibroblast growth factor. Cells were harvested at $80 \%$ confluence and

\begin{tabular}{lll} 
Table 3 & Patient satisfaction survey & \\
\hline Question & Answer & Score \\
\hline Are you satisfied with the quality of & Excellent & 1 \\
your daily life after an injection of & Very & 2 \\
ALLO-ASCs into the anal sphincter? & Good & \\
& Good & 3 \\
& Fair & 4 \\
& Poor & 5 \\
\hline
\end{tabular}

ALLO-ASC, allogeneic-adipose-derived mesenchymal stem cells. subcultured with 3 or 4 times of passage. After the cells were harvested via trypsinisation, ALLO-ASCs were packaged into single vials. The manufacturing process was performed by following the Good Manufacturing Practices of MFDS. Following these guidelines, before releasing the ALLO-ASCs, ample testing to assess for cell appearance, purity, viability, identification, potency and content is carried out. The safety of ALLO-ASCs from accidental contamination during the procedure is assessed by the test, for mycoplasma, viruses, bacteria and fungi.

\section{Intervention}

This trial is based on the injection of ALLO-ASCs into the anal sphincter in patients with faecal incontinence. In the safety test, the investigator begins to inject ALLO-ASCs into the anal sphincter of $3 \times 10^{7}$ cells, $6 \times 10^{7}$ cells and $9 \times 10^{7}$ cells in each group, sequentially. Fibrin glue, which is composed of $3 \mathrm{~mL}$ of fibrinogen and $0.8 \mathrm{~mL}$ of thrombin, is used to make a mixed solution of ALLO-ASCs. The numbers of ALLO-ASCs in each group are controlled by the concentration between a diluted solution and ALLO-ASCs. The final $6 \mathrm{~mL}$ of mixed solution is prepared for ALLO-ASC injection. Under spinal anaesthesia, the patient is positioned into a jack-knife position. Before injection, ALLO-ASCs are measured and prepared in a 21 gauge needle according to the experimental dose. After exposing the anal canal, two-thirds of the ALLO-ASCs are evenly injected into the internal anal sphincter in four directions (3, 6, 9 and 12 o'clock). The investigator performs a digital rectal examination to assess the condition of the injected anal sphincter. Then, the remaining dose of ALLO-ASCs is injected into the external anal sphincter, as demonstrated in figure 2. All procedures of the safety test are the same, except with a different dose of ALLO-ASCs injection by dose escalation. After finishing the safety test, the investigator assesses a safe dose that satisfies the most effective clinical outcomes. Then, this determined amount of ALLO-ASCs will be used in the experimental group in the following efficacy test.

In the efficacy test, the investigator injects a $6 \mathrm{~mL}$ mixed solution of ALLO-ASCs with fibrin glue into the anal sphincter of patients in the experimental group, using a dual syringe injection kit. In the placebo group, the patients are injected with $0.9 \%$ normal saline mixed with fibrin glue. In this study, fibrin glue is used for the mixed solution of ALLO-ASCs because it can sustain functional survival of mesenchymal stem cells and facilitates cell attachment, proliferation, differentiation and tissue formation as a cell delivery vehicle. ${ }^{17}{ }^{18}$ However, it is injected in the experimental and the control group, to exclude its effect for the symptoms of faecal incontinence. The injection techniques into the anal sphincter are the same with the safety test above. Three hours after the injection, the investigator performs a digital rectal examination and assesses both local tolerability and adverse events. 


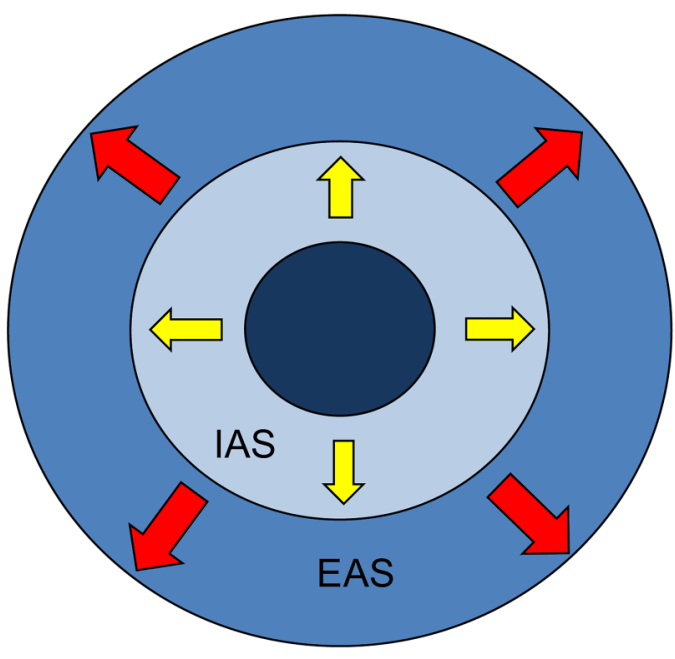

Figure 2 The site of ALLO-ASC injection in the anal sphincter. IAS, internal anal sphincter; EAS, external anal sphincter. Black arrow, the direction of the ALLO-ASC injection.

\section{End points of the study}

Primary end point

- To assess a safe dose of ALLO-ASCs injection in the anal sphincter, using dose escalation

\section{Secondary end points}

- To compare the efficacy of ALLO-ASCs injection with fibrin glue against $0.9 \%$ normal saline injection with fibrin glue

- To assess local tolerability and toxicity after ALLO-ASC injection into the anal sphincter muscle

\section{Safety assessment and reporting of adverse events}

Adverse events and safety assessment are evaluated at every visit after the ALLO-ASC injection. The investigator has a duty to report adverse events and protect patients who participate in this trial. Adverse events and their associations with injected materials are reported according to the WHO toxicity scale. Severe adverse events that result in life-threatening and prolonged disabled conditions, should be reported to the IRB by the investigator.

\section{Drop out}

Participants have the right to drop out of the trial at any time without stating any reason. Moreover, the patients may be dropped out because of medical or other reasons as follows:

- By the investigator, for the participant's health and well-being

- Violation of selection standard

- ALLO-ASC injection is over $24 \mathrm{~h}$ after the production date

- Owing to development of disease, which can affect the results of the clinical trial

- Worsening of disease

- A situation that is related to the exclusion criteria.

\section{Follow-up of study}

The patient visits the outpatient clinic after intervention at the postallocation period and the follow-up period. During the postallocation period, patients are assessed at the 1st, 4th and 8th weeks after intervention. In the safety test, the patient is assessed for clinical efficient outcomes at the 8th week after intervention. Then, patients are followed up at the 4th, 6th, 9th and 12th months, additionally. The basic methods to evaluate postintervention outcomes are similar between the safety and efficacy tests. Details of the examinations are summarised as follows:

- Physical examination, vital signs, digital rectal examination, local tolerability, Wexner score, adverse events, patient satisfaction survey and FIQL: every visit

- Serological and biochemical test, urinalysis: 8 weeks, 6th and 12th months

- Urine $\beta$-hCG: 8 weeks, 12th month

- Immunological test (CD4/CD8): 1st and 4th weeks

- Endorectal ultrasonography: 4th week and 12th month

- Anorectal manometry: every visit from the 4th week after intervention.

\section{Data collection and monitoring}

The committee supervises data collection and management in all procedures during the trial. All data are collected by an appointed researcher who is approved by the committee. They are monitored by the Standard Operating Procedures (SOPs) of the Korean Good Clinical Practice (KGCP) and ICH guidelines. Interim analysis is performed in the first year to assess the safety of ALLO-ASC injection into the anal sphincter.

\section{Outcome assessment}

In the safety evaluation, the toxicity grade is assessed by the WHO toxicity scale. Immunological response is examined by comparing $\mathrm{CD} 4 / \mathrm{CD} 8$ ratio on the 1 st and 4th weeks after the ALLO-ASC injection. In addition, local tolerability is evaluated by whether there are clinical signs of skin eruption, infection, immunological reaction or carcinogenesis, by physical examination.

The improvement of clinical symptoms is assessed by the Wexner score and FIQL. According to these questionnaires, conducted at every visit, the scores are compared before and after injection. If the Wexner score and FIQL both have statistically significant differences in their results at every visit or they are within normal range after treatment, it is regarded as an improved status.

Endorectal ultrasonography is utilised to assess the integrity of both external and internal anal sphincter, and anatomical abnormalities of the anal canal. The result is reported as a normal or an abnormal appearance after the examination. On the other hand, anorectal manometry is utilised to evaluate the functional outcomes of the anal sphincter after ALLO-ASC injection. Resting pressure, squeezing pressure, rectoanal inhibitory reflex (RAIR), rectal sensitivity and rectal 
capacity, are assessed. Each factor is assessed for statistical significance comparing preinjection and postinjection of ALLO-ASC status in all patients.

The patient satisfaction survey is used to assess subjective symptoms of each patient. The changes of the score are compared throughout each visit statistically.

\section{Ethics and dissemination}

This trial is conducted following the Good Clinical Practice guidelines and the principles of the Declaration of Helsinki. This study will be disseminated in peerreviewed journals and presented at a colorectal conference.

\section{DISCUSSION}

Faecal incontinence is a devastating condition that may cause social isolation of a patient, and impairs their quality of life by creating embarrassment and anxiety. According to a cost analysis of faecal incontinence, it is a substantial economic burden to society, averaging $\$ 4110$ per patient, annually. ${ }^{19}$ Furthermore, as ours is becoming a progressively ageing society, the increased incidence of faecal incontinence can have a negative impact on the public health system. However, the efficiency of treatments for faecal incontinence, such as medical therapy, biofeedback, sacral nerve stimulation and sphincteroplasty, have so far been limited and unsatisfactory. ${ }^{20}$ In this respect, stem cell therapy has emerged as a new treatment option for faecal incontinence. Since the anal sphincter degenerates with age, injection of mesenchymal stem cells into the anal sphincter has the potential to improve contractility as well as to enhance regeneration of the anal sphincter, theoretically. There are several recent reports to support the regenerative effect of mesenchymal stem cells on the anal sphincter. According to the results of an experimental model by Lorenzi et $a l^{21}{ }^{21}$ bone marrow-derived mesenchymal stem cell injection improved muscle regeneration and contractility function of the anal sphincter. In a cryoinjured rat model, Kang et al reported that autologous muscle-derived stem cells enhanced contractility of the anal sphincter and differentiation of muscle masses at the stem cell injection sites.

In this study, we use ALLO-ASCs, which are obtained from human adipose tissue. ASCs are attractive cells because they are pluripotent and available in large quantities. ${ }^{22}$ Since MSCs can improve tissue repair though cell replacement and enhance the microenvironment through a paracrine effect, recent studies of autologous ASCs for Crohn's fistula showed favourable therapeutic outcomes in phase I and phase II studies. ${ }^{12}{ }^{13}$ 23-25 Garcia-Olmo et $a l^{24}$ reported that expanded ASCs combined with fibrin glue was effective and safe for a complex perianal Crohn's fistula, in a phase II clinical study. In addition, ASCs can help to regenerate anal sphincter tissues because the paracrine effect of MSCs differentiates it into tissue-specific cells by secreting various cytokines, chemokines and growth factors such as vascular endothelial growth factor-1, Insulin-like growth factor- 1 and epidermal growth factor. ${ }^{26} 27$ The characteristics of ASCs, with self-renewal ability and tissue regeneration, are expected to enhance the contractility of the anal sphincter in patients with faecal incontinence.

Previous autologous ASC studies were performed by extraction of fat tissues by liposuction from each patient to prepare injected ASCs. Since patients suffered from painful and inconvenient procedures, previous clinical trials using autologous ASCs for faecal incontinence failed and were terminated due to insufficient enrolment (NCT01011686). In this study, we will use allogeneic mesenchymal stem cells, which are more convenient to prepare than ASCs since they are readymade products. In addition, because faecal incontinence develops mostly in elderly people due to degeneration of the anal sphincter, ALLO-ASCs made from young, healthy donors, have the advantage of isolating more vigorous progenitor cells than autologous ASCs do. ${ }^{28}$ Moreover, ALLO-ASCs have potential benefits to get more robust stem cells and a higher rate of both paracrine effect and cell engraftment than autologous ASCs do. ${ }^{29}$ In these aspects, the results of this study will have an impact on treating faecal incontinence because ALLO-ASCs have theoretical potential for regeneration of the anal sphincter.

Regarding their immunological aspects, MSCs have immunosuppressive properties that are transplantable in patients with HLA-incompatibility. ${ }^{30}$ Le Blanc $e t a l^{30}$ reported that MSCs do not lead to alloreactive lymphocyte proliferative responses as well as the modulation of the immune response. The immunoprivileged characteristics of MSCs in vitro can allow ALLO-ASCs in clinical use. ${ }^{32}$ However, there has been a concern that allogeneic MSCs can be altered from an immunoprivileged to an immunogeneic condition by biphasic immune response. $^{29}$ In this study, the concentration of ALLO-ASCs used for local injection is not adequate to alter the immune response. Although there is a lack of knowledge regarding long-term outcomes after using ALLO-ASCs, we expect that an ALLO-ASC injection into the anal sphincter is safe and feasible, and without an immune response.

Malignant transformation of MSCs has been debated because immunosuppressive characteristics of MSCs can facilitate tumourigenesis. ${ }^{32}$ Rubio $e t a l^{33}$ reported that adipose tissue-derived MSCs could have immortalisation and spontaneous transformation from long-term in vitro expansion. However, there has so far been a lack of research on the potential dangers of tumourigenicity from MSCs. Further research on the long-term outcomes of MSCs is necessary.

This study has the limitation of a small sample size in a single centre, as it is a pilot randomised controlled trial. Although the study population was determined by 
traditional $3+3$ dose escalation and sample size calculation, it has a limitation to draw a general conclusion for the effect of ALLO-ASCs. However, this study is the first clinical trial to use ALLO-ASCs in patients with faecal incontinence. The results of this pilot study can contribute in determining a safe dose of ALLO-ASCs in clinical use. In addition, it will be possible to expand it to future clinical trials using ALLO-ASCs for the treatment of faecal incontinence.

In conclusion, it is meaningful that our study is the first to investigate the effect of ALLO-ASCs for faecal incontinence by a randomised, prospective clinical trial. We expect that our results of this research can illuminate more efficient and convenient methods to overcome the limits of previous treatments for faecal incontinence.

Acknowledgements The authors thank MiSun Park (professional editor) for reviewing and editing the English of this manuscript.

Contributors SHB is the principal investigator, responsible for conception, design and processing of this trial. EJP contributed by writing the manuscript and carrying out the trial. JK participated in the protocol validity and conducting of this trial.

Funding This research is supported by a grant from the Korea Health Technology R\&D Project through the Korea Health Industry Development Institute (KHIDI), funded by the Ministry of Health \& Welfare, Republic of Korea (grant number: Hl14C3379).

Competing interests None declared

Patient consent Obtained.

Ethics approval The study protocol was approved by the Ministry of Food and Drug Safety (MFDS), and the Ministry of Health \& Welfare. The informed consent form was approved by the institutional review board of Gangnam Severance Hospital (IRB Number 3-2014-0271).

Provenance and peer review Not commissioned; externally peer reviewed.

Data sharing statement We will share the data after the trial is finished. Additional details of the study protocol can be requested from the corresponding author.

Open Access This is an Open Access article distributed in accordance with the Creative Commons Attribution Non Commercial (CC BY-NC 4.0) license, which permits others to distribute, remix, adapt, build upon this work noncommercially, and license their derivative works on different terms, provided the original work is properly cited and the use is non-commercial. See: http:// creativecommons.org/licenses/by-nc/4.0/

\section{REFERENCES}

1. Whitehead WE, Wald A, Diamant NE, et al. Functional disorders of the anus and rectum. Gut 1999;45(Suppl 2):II55-9.

2. Bharucha AE, Dunivan G, Goode PS, et al. Epidemiology, pathophysiology, and classification of fecal incontinence: state of the science summary for The National Institute of Diabetes and Digestive and Kidney Diseases (NIDDK) workshop. Am J Gastroenterol 2015;110:127-36.

3. Johanson JF, Lafferty J. Epidemiology of fecal incontinence: the silent affliction. Am J Gastroenterol 1996;91:33-6.

4. Jorge JM, Wexner SD. Etiology and management of fecal incontinence. Dis Colon Rectum 1993;36:77-97.

5. Engel BT, Nikoomanesh P, Schuster MM. Operant conditioning of rectosphincteric responses in the treatment of fecal incontinence. N Engl J Med 1974;290:646-9.

6. Bliss DZ, Jung HJ, Savik K, et al. Supplementation with dietary fiber improves fecal incontinence. Nurs Res 2001;50:203-13.

7. Matzel KE, Stadelmaier U, Hohenfellner M, et al. Electrical stimulation of sacral spinal nerves for treatment of faecal incontinence. Lancet 1995;346:1124-7.
8. Kang SB, Lee HN, Lee JY, et al. Sphincter contractility after muscle-derived stem cells autograft into the cryoinjured anal sphincters of rats. Dis Colon Rectum 2008;51:1367-73.

9. Frudinger A, Kolle D, Schwaiger W, et al. Muscle-derived cell injection to treat anal incontinence due to obstetric trauma: pilot study with 1 year follow-up. Gut 2010;59:55-61.

10. Romaniszyn M, Rozwadowska N, Nowak M, et al. Successful implantation of autologous muscle-derived stem cells in treatment of faecal incontinence due to external sphincter rupture. Int $J$ Colorectal Dis 2013;28:1035-6.

11. Frudinger A, Pfeifer J, Paede J, et al. Autologous skeletal-muscle-derived cell injection for anal incontinence due to obstetric trauma: a 5-year follow-up of an initial study of 10 patients. Colorectal Dis 2015;17:794-801.

12. Cho YB, Lee WY, Park KJ, et al. Autologous adipose tissue-derived stem cells for the treatment of Crohn's fistula: a phase I clinical study. Cell Transplant 2013;22:279-85.

13. Lee WY, Park KJ, Cho YB, et al. Autologous adipose tissue-derived stem cells treatment demonstrated favorable and sustainable therapeutic effect for Crohn's fistula. Stem Cells 2013;31:2575-81.

14. Puissant B, Barreau C, Bourin $\mathrm{P}$, et al. Immunomodulatory effect of human adipose tissue-derived adult stem cells: comparison with bone marrow mesenchymal stem cells. Br J Haematol 2005;129:118-29.

15. Le Tourneau C, Lee JJ, Siu LL. Dose escalation methods in phase cancer clinical trials. J Natl Cancer Inst 2009;101:708-20.

16. Rockwood TH, Church JM, Fleshman JW, et al. Fecal Incontinence Quality of Life Scale: quality of life instrument for patients with fecal incontinence. Dis Colon Rectum 2000;43:9-16; discussion 16-17.

17. Kim I, Lee SK, Yoon JI, et al. Fibrin glue improves the therapeutic effect of MSCs by sustaining survival and paracrine function. Tissue Eng Part A 2013;19:2373-81.

18. Guo HD, Wang HJ, Tan YZ, et al. Transplantation of marrow-derived cardiac stem cells carried in fibrin improves cardiac function after myocardial infarction. Tissue Eng Part A 2011;17:45-58.

19. Xu X, Menees SB, Zochowski MK, et al. Economic cost of fecal incontinence. Dis Colon Rectum 2012;55:586-98.

20. Wald A. Clinical practice. Fecal incontinence in adults. N Engl J Med 2007;356:1648-55.

21. Lorenzi B, Pessina F, Lorenzoni $P$, et al. Treatment of experimental injury of anal sphincters with primary surgical repair and injection of bone marrow-derived mesenchymal stem cells. Dis Colon Rectum 2008;51:411-20.

22. Mizuno $\mathrm{H}$, Hyakusoku $\mathrm{H}$. Mesengenic potential and future clinical perspective of human processed lipoaspirate cells. J Nippon Med Sch 2003;70:300-6.

23. Garcia-Olmo D, Garcia-Arranz M, Herreros D, et al. A phase I clinical trial of the treatment of Crohn's fistula by adipose mesenchymal stem cell transplantation. Dis Colon Rectum 2005;48:1416-23.

24. Garcia-Olmo D, Herreros D, Pascual I, et al. Expanded adipose-derived stem cells for the treatment of complex perianal fistula: a phase II clinical trial. Dis Colon Rectum 2009;52:79-86.

25. Wang J, Liao L, Tan J. Mesenchymal-stem-cell-based experimental and clinical trials: current status and open questions. Expert Opin Biol Ther 2011:11:893-909.

26. Rehman J, Traktuev D, Li J, et al. Secretion of angiogenic and antiapoptotic factors by human adipose stromal cells. Circulation 2004;109:1292-8.

27. Chen L, Tredget EE, Wu PY, et al. Paracrine factors of mesenchymal stem cells recruit macrophages and endothelial lineage cells and enhance wound healing. PLOS ONE 2008;3:e1886.

28. Hare JM, Fishman JE, Gerstenblith G, et al. Comparison of allogeneic vs autologous bone marrow-derived mesenchymal stem cells delivered by transendocardial injection in patients with ischemic cardiomyopathy: the POSEIDON randomized trial. JAMA 2012;308:2369-79.

29. Huang XP, Sun Z, Miyagi Y, et al. Differentiation of allogeneic mesenchymal stem cells induces immunogenicity and limits their long-term benefits for myocardial repair. Circulation 2010;122:2419-29.

30. Le Blanc K, Tammik C, Rosendahl K, et al. HLA expression and immunologic properties of differentiated and undifferentiated mesenchymal stem cells. Exp Hematol 2003;31:890-6.

31. McIntosh K, Zvonic S, Garrett S, et al. The immunogenicity of human adipose-derived cells: temporal changes in vitro. Stem Cells 2006;24:1246-53.

32. Uccelli A, Moretta L, Pistoia V. Mesenchymal stem cells in health and disease. Nat Rev Immunol 2008;8:726-36.

33. Rubio D, Garcia-Castro J, Martin MC, et al. Spontaneous human adult stem cell transformation. Cancer Res 2005;65:3035-9. 